\title{
TECHNOLOGICAL CHANGE AND THE TIMING OF MITIGATION MEASURES
}

\author{
Arnulf Grübler \\ Sabine Messner \\ International Institute for Applied Systems Analysis \\ Laxenburg, Austria
}

RR-99-1

January 1999

Reprinted from Energy Economics, Volume 20, Numbers 5, 6, pp. 495-512, December 1998.

International Institute for Applied Systems Analysis, Laxenburg, Austria Tel: +432236 807 Fax: +43223673148 E-mail: publications@iiasa.ac.at 
Research Reports, which record research conducted at IIASA, are independently reviewed before publication. Views or opinions expressed herein do not necessarily represent those of the Institute, its National Member Organizations, or other organizations supporting the work.

Reprinted with permission from Energy Economics, Volume 20, Numbers 5, 6, pp. 495-512, December 1998.

Copyright (c) 1998 with permission from Elsevier Science.

All rights reserved. No part of this publication may be reproduced or transmitted in any form or by any means, electronic or mechanical, including photocopy, recording, or any information storage or retrieval system, without permission in writing from the copyright holder. 


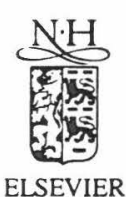

Energy Economics

Energy Economics 20 (1998) 495-512

\title{
Technological change and the timing of mitigation measures
}

\author{
Arnulf Grübler*, Sabine Messner \\ Environmentally Compatible Energy Strategies Project, International Institute for Applied Systems \\ Analysis, A-2361 Laxenburg, Austria
}

\begin{abstract}
We use a coupled carbon-cycle and energy systems engineering model to analyze the future time path of carbon emissions under an illustrative $\mathrm{CO}_{2}$ concentration stabilization limit of $550 \mathrm{ppm}$. Our findings confirm the emission pattern as found by WRE: global emissions rise initially, pass through stabilization, in order to decline in the second half of the 21st century. We show that for a given $\mathrm{CO}_{2}$ concentration target, emission trajectories within an intertemporal optimization framework depend mainly on two factors: the discount rate, and the representation of technological change as either static or dynamic. We obtain a similar near-term emission time path as WRE when using a model with static technology and a discount rate of $7 \%$. We obtain a trajectory with lower emissions in the near-term when using a lower discount rate and/or treating technology dynamics endogenously in the model. We briefly outline a model that endogenizes technological change through learning curves. We then compare differences in emission trajectories between alternative model formulations of technological change. They are sufficiently small as to be of secondary importance when compared to treating $\mathrm{CO}_{2}$ concentration stabilization as an inter-temporal optimization problem or not. Whereas our results confirm the computational results of WRE, we arrive nonetheless at different policy conclusions. If long-term emission reduction is the goal, we cannot follow 'business as usual' even in the short-term. Action needs to start now. Action does not necessarily mean aggressive short-term emission reductions but rather enhanced R \& D and technology demonstration efforts that stimulate technological learning. These are the necessary preconditions that long-term reduction targets can be met with improved technology and at costs lower than today. We close by pointing out two further
\end{abstract}

\footnotetext{
* Corresponding author. Tel.: +432236 807470; fax: +432236 71313; e-mail: gruebler@iiasa.ac.at 
critical issues: uncertainty, and the possible mismatch between the world of economic models and that of climate policy. (c) 1998 Elsevier Science B.V. All rights reserved.

JEL classifications: Q4; Q2; C61; O31

Keywords: Intertemporal optimization; $\mathrm{CO}_{2}$ emission reduction; Timing of emission abatement; Endogenous technological change

\section{Introduction}

In an influential article Wigley, Richels and Edmonds (1996, WRE) have constructed alternative emission pathways for a range of $\mathrm{CO}_{2}$ concentration stabilization targets. WRE argue that the emission paths derived from the IPCC WGI stabilization exercises (Schimmel et al., 1995) imply too drastic short-term emission reductions that may be either difficult to achieve, or be too costly as leading to premature retiring of existing capital. For instance, the IPCC WGI scenario stabilizing at 550 ppmv (by 2150 ) reaches a maximum emission level below $9 \mathrm{GtC}$ in 2060, while unconstrained 'business as usual' scenarios such as the IPCC IS92a scenario (Pepper et al., 1992) reach emission levels of more than $10 \mathrm{GtC}$ already by 2020 . WRE argue that drastic near- to medium-term reduction measures are not required. They demonstrate that emission trajectories with higher short-term trends (and corresponding lower long-term emissions) yield similar long-term $\mathrm{CO}_{2}$ stabilization targets. Model analyses performed at IIASA confirm this view. However, we arrive at a different policy interpretation of these model results. This difference primarily stems from our different interpretation of technological change as an endogenous process. Rather than following as long as possible a 'business as usual' path (e.g. along the trajectory of the IS92a scenario), one needs early action to prepare the longer-term departure from 'business as usual'. This early action does not necessarily imply drastic emission reductions, but rather enhanced R \& D and technology demonstration efforts to assure that long-term emission reductions can be achieved with improved technologies and with lower costs than today.

\section{Timing of mitigation measures}

We have replicated WRE's analysis using a coupled carbon cycle and energy systems engineering model for an illustrative $\mathrm{CO}_{2}$ concentration stabilization scenario at $550 \mathrm{ppm}$ (by 2150). Based on this analysis we discuss below that the timing of GHG mitigation measures depends on a variety of factors. The most salient ones include the following.

1. The time horizon by which stabilization is to be achieved. Obviously, a longer horizon leaves more time for mitigation measures to be implemented. In an extreme case, consider for instance, pushing the stabilization date further out, 
say from 2150 to the year 2300 . This would allow to do without any mitigation efforts over the next couple of decades whilst still remaining within the overall goal of concentration stabilization some time in the future. Whilst recognizing the long time constants involved in anthropogenic alterations of the carbon cycle, we feel that arguing over an arbitrarily set date by which $\mathrm{CO}_{2}$ concentrations should be stabilized is of little use both for economic analysis and policy. Balancing near- versus long-term mitigation efforts inevitably entails an attempt of finding an intertemporal optimum, hence discounting (see discussion below). Extending the analysis hundreds of years out into the future is of little relevance for discussing policy choices for the next one or two decades. Such long time horizons also exceed current algorithmic and computational capabilities, i.e. with discounting it is basically impossible to discriminate between alternative long-term solutions when costs and benefits are expressed in present day values. ${ }^{1}$

2. The discount rate used for intertemporal comparison. High discount rates tend to postpone mitigation measures by stronger emphasis of short-term over long-term costs. Apart from being of obvious influence, the choice of an appropriate discount rate remains open to debate. Hence, we perform calculations for a range of discount rates of 3,5 , and $7 \%$, respectively.

3. Rates of future technological change. Higher rates of technological change can improve the technical and economic performance of mitigation technologies such as energy conservation and of low- and zero-carbon options. In our analysis we first develop a base case scenario without any carbon constraint. We are able to replicate a typical 'business as usual' emission trajectory, under the assumption of static technology, that limit accessibility of oil and gas resources beyond currently known recoverable quantities and with technology costs assumptions that do not improve over time. It goes without saying that we consider such a 'business as usual' scenario highly improbable and at odds with historical experience (Grübler and Nakićenović, 1996).

4. The representation of technological change. An endogenous representation of technological change allows technology characteristics to be influenced by intervening actions. Technological change does not fall from heaven, but rather results from dedicated action: $\mathrm{R} \& \mathrm{D}$, technology demonstration, and investments. Earlier action, i.e. R \& D expenditures and investments, can enhance the future performance of mitigation technologies. Earlier action is also required considering the long lead-times between $\mathrm{R} \& \mathrm{D}$, technology demonstration and pervasive diffusion of new energy technologies, that can span many decades. This constitutes the main difference in our qualitative interpretation of model results that quantitatively confirm the WRE calculations. In essence, we argue that WRE's conclusion to follow over the near-term a 'business as usual'

\footnotetext{
${ }^{1}$ Because of this we limit our analysis to the period 1990-2100. In order to assure comparability with the calculations of IPCC WGI and WRE we adopt a (conservative) $\mathrm{CO}_{2}$ stabilization target of $530 \mathrm{ppm}$ by the year 2100 . This lower limit assures that a target of $550 \mathrm{ppm}$ by 2150 can be met under a continuation of a declining emissions trend in the post 2100 period.
} 
trajectory corresponds to a viewpoint of exogenous technological change. 'Autonomous' technological change will lower future mitigation costs. Hence, it is sufficient to 'wait and see' and not to engage in costly investments in mitigation technologies in the short-term. We argue, that without short-term investments, long-term technology improvements will not materialize.

5. Relationship to other pollutants. $\mathrm{CO}_{2}$ abatement strategies depend also on whether their effects (i.e. secondary benefits) on other pollutant emissions are included in the analysis or not. Our results for instance indicate that $\mathrm{CO}_{2}$ emissions will be (slightly) lower in scenarios of active sulfur reduction policies in response to acidification concerns. ${ }^{2}$ Based on current understanding (IPCC, 1995, 1996), sulfur reduction measures will however, enhance the global warming signal of a given GHG emissions trajectory because of the reduced cooling effect of sulfate aerosols (Rogner and Nakićenović, 1995).

\section{Replicating WRE}

In order to replicate the emission trajectories of WRE we have used an existing model set available at IIASA. The modelling exercise uses the bottom-up dynamic linear programming energy sector model MESSAGE III (Messner and Strubegger, 1995) with an integrated carbon cycle component, that has been developed on the basis of MAGICC (Wigley, 1991).

We first create (two variants of) a reference scenario without any constraints on carbon emissions. We adopt a high demand scenario ('high growth' case A scenario of IIASA-WEC, 1995), coupled with a static (i.e. limited) resource base (from the coal intensive A2 scenario variant of the IIASA-WEC (1995) study) and static technologies, i.e. costs of fossil and non-fossil technologies do not change compared to current levels. ${ }^{3}$ In such a scenario global energy sector carbon emissions would rise to some $22 \mathrm{Gt}$ (giga, i.e. billion tons elemental) carbon by the year 2100 . With increasing carbon emissions, also sulfur emissions would rise in the scenario: to some 200 million tons (elemental) sulfur by the year 2100. Considering the significant acidification impacts of such a scenario (cf. Amann et al., 1995; Posch et al., 1996), we have also investigated a scenario subvariant with drastic limits on

\footnotetext{
${ }^{2}$ In an investigation of conflicts and synergies of $\mathrm{CO}_{2}$ and $\mathrm{SO}_{2}$ mitigation strategies, Messner (1997b) performs alternative model calculations of limits on global $\mathrm{SO}_{2}$ emissions. Setting a stringent constraint on $\mathrm{SO}_{2}$ emissions at $25 \%$ of the 1990 level, $\mathrm{SO}_{2}$ abatement measures and fuel and technology switching are applied. By 2100 , limiting $\mathrm{SO}_{2}$ emissions results in $25 \%$ lower $\mathrm{CO}_{2}$ emissions than in the base case. Conversely, a limit on $\mathrm{CO}_{2}$ concentrations to $550 \mathrm{ppmv}$ (compared to 620 ppmv in the unconstrained case) implies a reduction in $\mathrm{SO}_{2}$ emissions to less than half of the original value. This drastic reduction is achieved by reducing coal use and applying more efficient and environmentally more benign coal-based technologies, like IGCCs, where $\mathrm{SO}_{2}$ removal is inherent to the (prior coal gasification) process.

${ }^{3}$ Cost parameters in the model are derived from a detailed statistical analysis of technology costs obtained from the IIASA technology inventory CO2DB (cf. Strubegger and Reitgruber, 1995).
} 
Table 1

Two reference scenarios of unabated carbon emissions: IPCC IS92a (Pepper et al., 1992) and a static technology scenario based on the demands of the high growth case A scenario of the IIASA-WEC (1995) set of scenarios. The range of primary energy use and emissions for the static technology scenario correspond to two scenario subvariants, with and without control of sulfur emissions

\begin{tabular}{lcrc}
\hline & Year & IS92a & Static technology $^{\mathrm{a}}$ \\
\hline GWP $\left(10^{12} \$\right)$ & 2050 & 92 & 100 \\
Primary energy (EJ) & 2100 & 243 & 300 \\
& 2050 & 934 & $1064-1073^{\mathrm{b}}$ \\
Energy sector emissions GtC & 2100 & 1457 & $1660-1731^{\mathrm{b}}$ \\
MtS & 2050 & 13 & $14-15^{\mathrm{b}}$ \\
& 2100 & 20 & $19-22^{\mathrm{b}}$ \\
Cumulative carbon emissions 1990-2100 (all sources) & 2050 & 132 & $29-123^{\mathrm{b}}$ \\
\end{tabular}

${ }^{a}$ Demands based on high growth case A of the IIASA-WEC (1995) scenarios.

${ }^{b}$ Range corresponds to uncontrolled and controlled sulfur emissions, respectively.

${ }^{c}$ Non-energy sector emissions from IS92a.

sulfur emissions. As a 'byproduct' of the sulfur reduction efforts also carbon emissions decline slightly (to some $19 \mathrm{GtC}$ by 2100 ) due to interfuel substitution effects, e.g. coal being replaced by nuclear power in electricity generation.

Both scenario variants bracket reasonably well the emission profile of the 'business as usual' scenario IS92a, as shown in Table 1 and Fig. 1. We have used a discount rate of $5 \%$ in our calculations. Apart from the fact, that a typical 'business as usual' emissions scenario, in terms of our model assumptions translates into a combination of high economic growth combined with static technologies (which we feel both improbable and inconsistent with growth theory), our two base case scenarios serve as a useful and comparable starting point to calculate the impacts of $\mathrm{CO}_{2}$ emission constraints.

The reader is alerted to differences in base year (1990) emissions between our calculations and those of WRE and IPCC WGI. Our base year emissions of 7.5 GtC (compared to 6.9 in WRE and IPCC WGI) comprise 6 GtC from burning of fossil fuels (and flaring of natural gas), $0.2 \mathrm{GtC}$ from manufacturing of cement, and an estimated $1.3 \mathrm{GtC}$ from land use changes (imposed exogenously on our model), consistent with the IPCC second assessment report (IPCC, 1995) and also in good agreement with the $7.4 \mathrm{GtC}$ global 1990 emissions of the IS92a scenario (Pepper et al., 1992).

We now impose limits on $\mathrm{CO}_{2}$ emissions in a similar way as done by WRE and the IPCC WGI stabilization exercises. ${ }^{4}$ We chose an illustrative mid-level stabilization target of $550 \mathrm{ppm}$ by 2150 . As our model calculations extend only to the year 2100 , we have lowered the stabilization target to $530 \mathrm{ppmv}$ by the year 2100 . This

\footnotetext{
${ }^{4}$ We assume full intertemporal and spatial flexibility of emission reductions. i.e. the model is free to choose emission reductions when and where these are cheapest.
} 


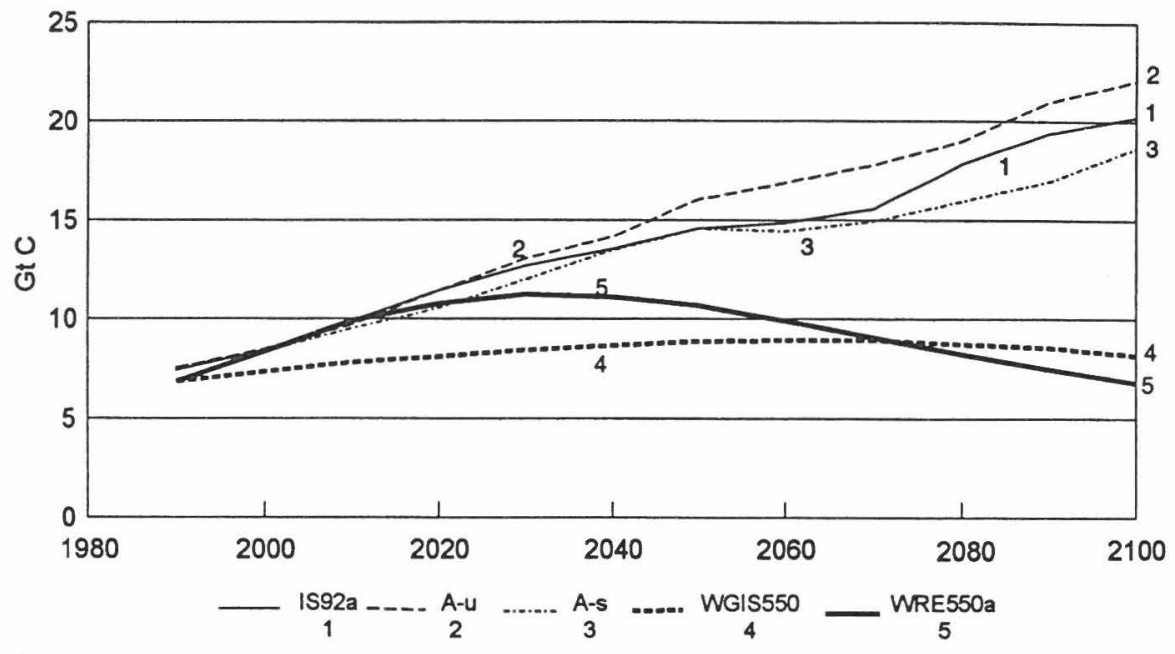

Scenarios:

1 IS92a (IPCC IS92s, no emission limits)

2 A_u (this study: unconstraint base case, demands from IIASA-WEC Scenario A)

3 A_s (this study: base case A_u with sulfur emission constraint, demands from IIASA-WEC Scenario A)

$4 \quad$ WGI S550 (IPCC WGI stabilization at $550 \mathrm{ppm}$ )

5 WRE 550a (WRE stabilization at $550 \mathrm{ppm}$ )

Fig. 1. Carbon emissions (all sources) IS92a, and two high growth scenarios with static technology with and without sulfur emission controls (in GtC). For comparison also two scenarios WRE (Wigley et al., 1996) and IPCC WGI (Schimmel et al., 1995) leading to stabilization of $\mathrm{CO}_{2}$ concentrations at $550 \mathrm{ppm}$ by 2150 are shown.

assures that with a continuation of our declining emission trajectories after 2100 the scenarios remain below $550 \mathrm{ppm}$ by 2150 , and hence comparable to the WRE and IPCC WGI calculations. (This shorter time horizon also explains why our emission trajectories are somewhat lower than WRE after 2060.) As our model includes only energy sector emissions, we have used the IS92a scenario's non-energy $\mathrm{CO}_{2}$ emission scenario as additional exogenous input to our calculations. ${ }^{5}$

This $\mathrm{CO}_{2}$ concentration limit translates into a need to drastically lower cumulative carbon emissions in the 1990 to 2100 period. Our scenarios yield cumulative $\mathrm{CO}_{2}$ emissions (all sources) between 943 to $988 \mathrm{GtC}$ across all carbon constraint

\footnotetext{
${ }^{5}$ For instance, $\mathrm{CO}_{2}$ emissions related to land-use changes in IS92a decrease from $1.3 \mathrm{GtC}$ in 1990 to zero by 2080 as tropical forests become progressively depleted. For our calculations we have assumed a zero emission flow beyond 2080 , i.e. as a conservative assumption we have not retained the negative carbon emission flux from land-use changes of the original IS92a scenario.

${ }^{6}$ Because of our shorter simulation horizon and the conservative cap of $530 \mathrm{ppm}$ by 2100 our cumulative emissions are slightly (between 3 and 15\%) lower compared to the WRE and IPCC WGI scenarios. The difference illustrates the influence of choosing alternative dates by which stabilization is to be achieved: 2150 in WRE and IPCC WGI versus 2100 in our case.
} 
cases analyzed, compared to 995 to $1103 \mathrm{GtC}$ in the IPCC WGI and WRE $550 \mathrm{ppm}$ stabilization scenarios over the same time period. ${ }^{6}$ In the unconstrained cases cumulative emissions between 1990 and 2100 are between 1567 to $1772 \mathrm{GtC}$ in our static technology scenarios compared to $1658 \mathrm{GtC}$ in IS92a (see Table 1).

\subsection{Varying discount rates}

We now vary the range of discount rates 3,5 , and $7 \%$ to simulate the effect of different time preferences. All $\mathrm{CO}_{2}$ emission trajectories show a persistent tendency to initially follow the original (unconstrained) trajectory, pass through a maximum, in order to decline thereafter as shown in Fig. 2.

Thus, our calculations confirm the findings of WRE. Calculating the intertemporal optimum of emission reduction with the help of a detailed 'bottom-up' energy model with static technology and a discount rate of $7 \%$, we obtain practically an identical short-term (1990-2030) emission path as WRE. Lowering the discount rate for intertemporal choice somewhat lowers short-term emission

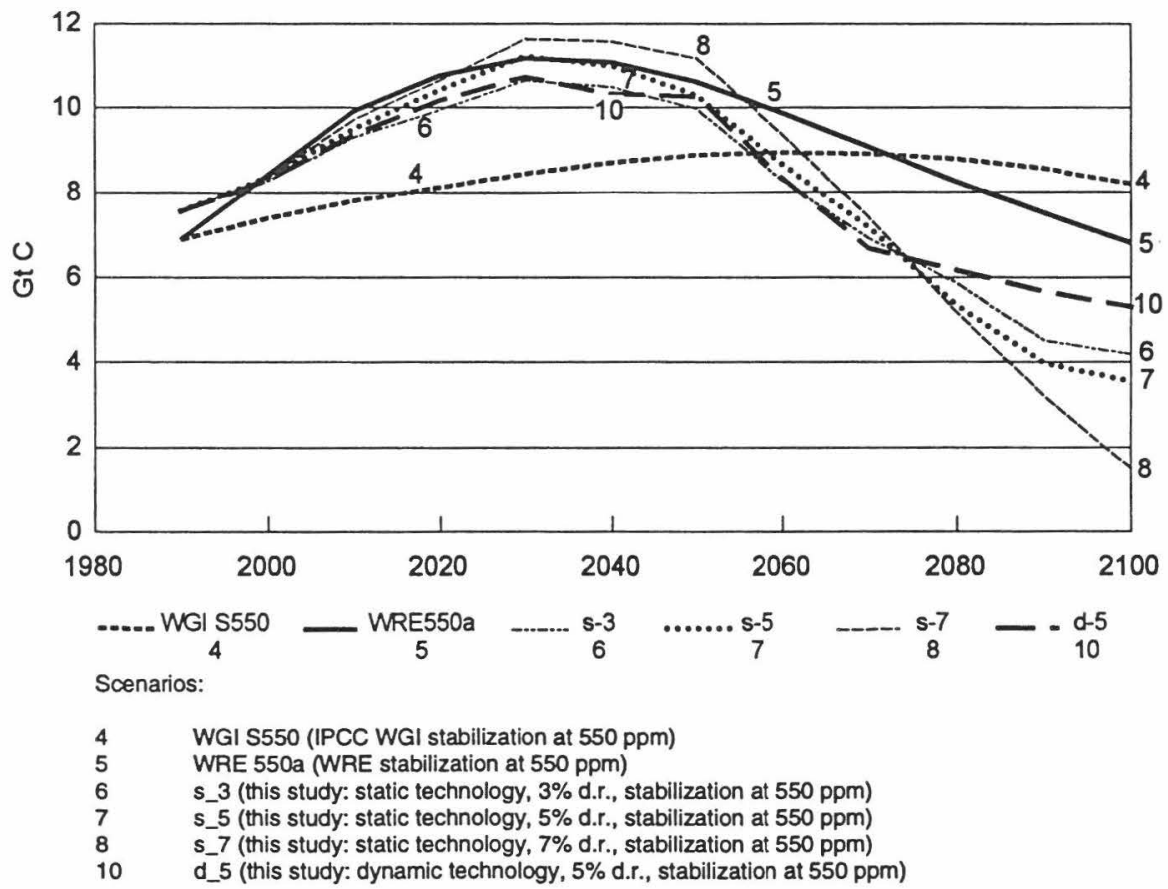

Fig. 2. Carbon emissions (all sources) for alternative scenarios reaching stabilization at 550 ppm by 2150. IPCC WGI, WRE, and our calculations with a static technology and 3, 5 (base case), and 7\% discount rate (in $\mathrm{GtC}$ ). Note in particular, the similarity of our time path to the WRE scenario and the difference of both scenarios to that of IPCC WGI. For comparison, also a model run with endogenized technology dynamic and a $5 \%$ discount rate is shown (see discussion below). 
paths, i.e. more emission reductions relative to the baseline scenario happen in the near-term. However, the basic pattern of emissions, and especially the striking contrast to the IPCC WGI emission trajectory (the gist of the WRE argument) remains basically unchanged. Over the next couple of decades emissions in a $\mathrm{CO}_{2}$ concentration stabilization scenario depart only gradually and slowly from the unconstraint reference scenario. This is both a result of the intertemporal optimization criterion adopted, as well as of the detailed capital vintage structure represented in our model. Because of the long lifetimes of energy technologies and infrastructures, capital stock turnover rates are slow. Long-term emissions constraints only translate slowly into departures from unconstraint emission scenarios.

The above findings are reassuring from a technical modeling and reproducibility viewpoint, but they offer little insight for the policy debate. We argue that such insight can only be gained once the most restricting assumption of our model reproducing WRE's quantitative findings is relaxed: the view of a static technology, or of technological change being exogenous to the economy.

\section{Endogenizing technological change}

\subsection{Technological learning}

The performance and productivity of technologies typically increase substantially as organizations and individuals gain experience with them. Long-studied in human psychology, technological learning phenomena were first described for the aircraft industry by Wright (1936), who reported that unit labor costs in air-frame manufacturing declined significantly with accumulated experience measured by cumulative production (output). ${ }^{7}$ Technological learning has since been analyzed empirically for numerous manufacturing and service activities including aircraft, ships, refined petroleum products, petrochemicals, steam and gas turbines, even broiler chickens. Learning processes have also been documented for a wide variety of human activities ranging from success rates of new surgical procedures to productivity in kibbutz farming and nuclear plant operation reliability (Argote and Epple, 1990). In economics, 'learning by doing' and 'learning by using' have been highlighted since the early 1960s (see e.g. Arrow, 1962; Rosenberg, 1982). Detailed studies track the many different sources and mechanisms of technological learning (for a succinct discussion of 'who learns what?' see Cantley and Sahal, 1980). ${ }^{8}$

Learning phenomena are generally described in the form of 'learning' or

\footnotetext{
${ }^{7}$ The aircraft industry however also provides examples that technological learning should not be taken for granted. The other side of 'learning by doing' is 'forgetting by not doing'. An example of 'negative' technological learning is provided by the Lockheed L-1011 Tristar aircraft (Argote and Epple, 1990). Production started in 1972 and reached 41 units in 1974. It subsequently dropped to six units in 1977, and then increased again thereafter. The drastic reduction in output led to large scale layoffs and the initially gained experience was lost with the staff turnover. As a result, the planes built in the early 1980 s were in real terms (after inflation) more expensive than those built in the early 1970s.
} 


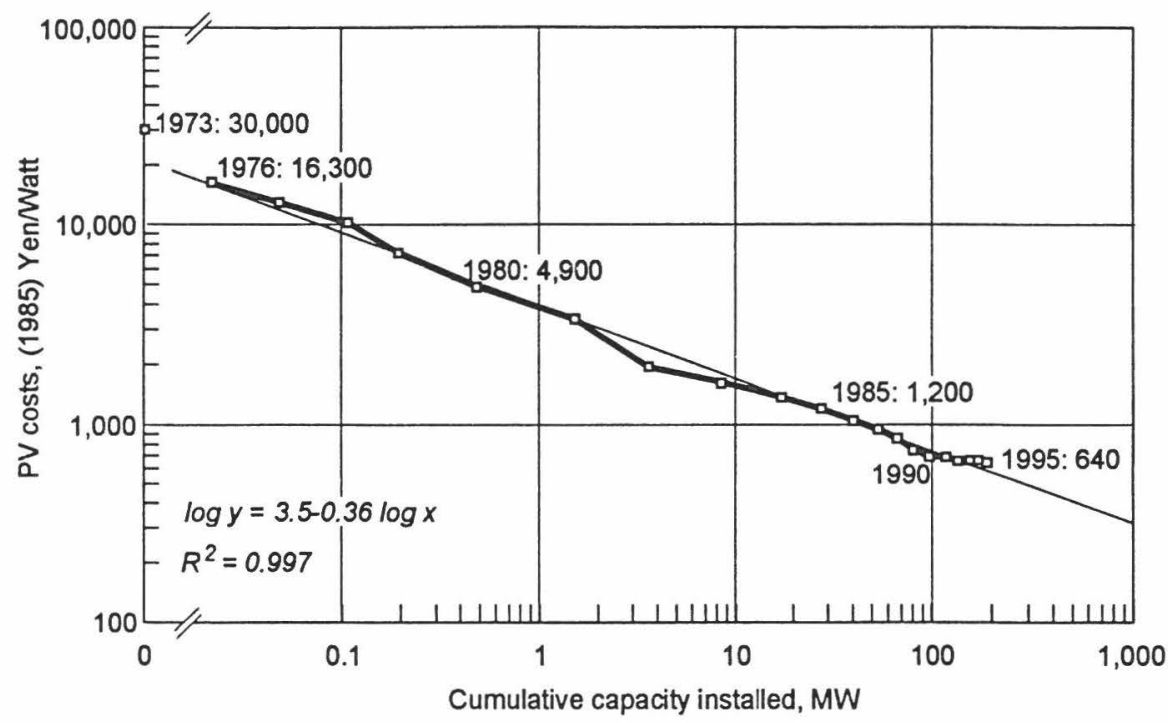

Fig. 3. Photovoltaic costs (1985 Yen per Watt installed) as a function of cumulative installed capacity (in MW), Japan 1976-1995. Data source: Watanabe (1995, 1997).

'experience' curves, where unit costs of production decline at a decreasing rate as experience is gained. Because learning depends on the actual accumulation of experience and not just on the passage of time, learning curves are generally measured as a function of cumulative output. Frequently, the resulting exponential decay function is plotted with logarithmically scaled axes so that it becomes a straight line (see Fig. 3). Because each successive doubling takes longer, such straight line plots should not be misunderstood to mean 'linear' progress that can be maintained indefinitely. Over time, cost reductions become smaller and smaller as each doubling requires more production volume. The potential for cost reductions becomes increasingly exhausted as the technology matures.

Technological learning is a classical example of 'increasing returns', i.e. the more experience is accumulated, the better the performance, the lower the costs of a technology, etc. However, because accumulation of experience takes ever longer

\footnotetext{
${ }^{8} \mathrm{~A}$ stylized taxonomy of technological learning mechanisms includes inter alia: learning by upscaling (e.g. steam turbines or generators), learning through mass production (e.g. the classical Model T Ford), and learning through both increasing scale and mass production, referred to here as 'continuous operation', i.e. the mass production of standardized commodities in plants of increasing size (e.g. transistors, or base chemicals like ethylene or PVC, where cost reductions through learning have been particularly spectacular, cf. Clair, 1983). This simple taxonomy is confirmed by a statistical analysis of learning rates across many technologies and products (Christiansson, 1995). Learning rates are typically twice as high for 'continuous operation' as for either upscaling or mass production learning processes alone.
} 
(cf. the increasingly 'packed' spacing of observations towards the 1990s in Fig. 3) and is more difficult to achieve, learning itself shows decreasing marginal returns.

Fig. 3 plots the costs of photovoltaic cells per (peak) kW capacity as a function of total cumulative installed capacity for Japan. Starting off from extremely high costs of some 30000 Yen (in 1985 prices) in the early 1970s, costs fell dramatically: from 16300 Yen in 1976 to 1200 Yen in 1985 (i.e. a factor close to 14 in less than 10 years), and then further to 640 Yen in 1995 (another factor 2 within the next 10 years). The resulting learning rate of over $30 \%$ reduction in costs per doubling of cumulative installed capacity is at the higher end of the range of learning rates observed in the empirical literature (cf. Argote and Epple, 1990; Christiansson, 1995). This high learning rate however is less surprising considering the infancy of the technology and the significant progress through $\mathrm{R} \& \mathrm{D}^{9}$ that should, in fact, not be separated from 'learning by doing' via investments.

\subsection{Modeling technological change}

Technological change can thus be expressed by a so-called progress ratio, i.e. the cost reduction achieved with a doubling of experience gained with a technology. The mathematical formulation is based on an exponential cost reduction:

$$
C(x)=a \times x^{-b}
$$

where $C(x)$ is the specific cost of the technology with $x$ cumulative installations, $a$ is the cost of the first unit, and $b$ is a so-called learning index. According to this formulation, a doubling of experience from 1 to 2 will yield specific costs of $a \times 2^{-b}$ the progress ratio being $2^{-b}$.

Despite overwhelming empirical evidence and solid theoretical underpinnings, learning phenomena have been explicitly introduced only into few models of intertemporal choice. The most likely explanation for this paucity of model applications is the difficulties of dealing algorithmically with the resulting non-convexities of the problem solution. A first detailed model formulation was suggested by Nordhaus and Van der Heyden (1983) to assess the potential benefits of enhanced R\&D efforts in new energy technologies such as the fast breeder reactor. A first full scale operational optimization model incorporating systematic technological learning was developed by Messner (1995) (see also Nakićenović, 1996, 1997; Messner, 1997). In a mixed-integer formulation, learning rates for a number of advanced electricity generating technologies were introduced into a linear programming model of the global energy system. These learning rates were assumed to be known ex ante. Hence, future technology costs depend solely on the amount of intervening investments that lead to increased installed capacity (experience), that, in turn, stimulates learning and subsequent cost reductions.

An extension of the above learning model to include both $\mathrm{R} \& \mathrm{D}$ as well as

\footnotetext{
${ }^{9}$ Note in particular the substantial cost decreases between 1973 and 1976 prior to any installation of demonstration units.
} 
uncertainty explicitly in a model of technology choice was carried out by Grübler and Gritsevskii (1997). There, technological learning is not only influenced by market shares and cumulative experience gained with a technology, but also by $\mathrm{R} \& \mathrm{D}$ efforts. A distinguishing feature of the model is that both $\mathrm{R} \& \mathrm{D}$ as well as learning by doing (e.g. via investments) are treated as interrelated, i.e. without prior R \& D and subsequent investments technology improvements cannot materialize. Another distinguishing characteristic of the model is that uncertainty is dealt with explicitly. Technological change in the model arises from diversification strategies vis à vis the uncertainties concerning potential improvement rates of technologies, energy demand, or even possible emergence of environmental limits (e.g. $\mathrm{CO}_{2}$ taxes).

\subsection{Simulating technology dynamics}

Approaches to include technological change into energy models usually concentrate on the use of static (i.e. time-constant) or exogenously given dynamic (i.e. improving over time) technology characteristics. The static approach completely ignores future improvements in technology cost or performance. Such model formulations inevitably lead to high emission futures, as illustrated by our base case simulations above.

Models of technology characteristics with exogenous dynamics predefine technology performance as exogenous to the model. With (often not explicitly identified) assumptions concerning possible (maximum) market penetration, time trajectories of economic and technical technology parameters are imposed exogenously on the model. This approach does not guarantee consistency between basic assumptions, which include cumulative installations of a technology to derive the changes in technology characteristics, and the results of the model, which also include new installations and consequently cumulative experience.

A typical result of models with exogenous dynamics and intertemporal choice is the deferral of investment decisions until the point in time when the technology is cheap enough to be competitive. Such results ignore the necessity to invest in expensive technology in its early phases, where niche markets or policy support need to be exploited to successfully introduce new technologies.

With endogenized technology dynamics, an intertemporal optimization model does not have the option to circumvent the early and expensive phases of technological development. If the decision to implement a new technology is taken later, technological learning also starts later. The technology matures later and the positive effects of learning materialize later. Consequently, in intertemporal optimization endogenizing technological change usually results in earlier, upfront investments into new technologies. The global optimum is reached when new and cheap technologies are developed at the earliest possible stage.

Fig. 4 shows an example of such results. Using a model with static technologies, neither advanced nuclear reactors nor solar PV cells are applied, since present costs and efficiencies of these technologies are not competitive at present nor become so in future. When exogenous technology dynamics, based on a slow 


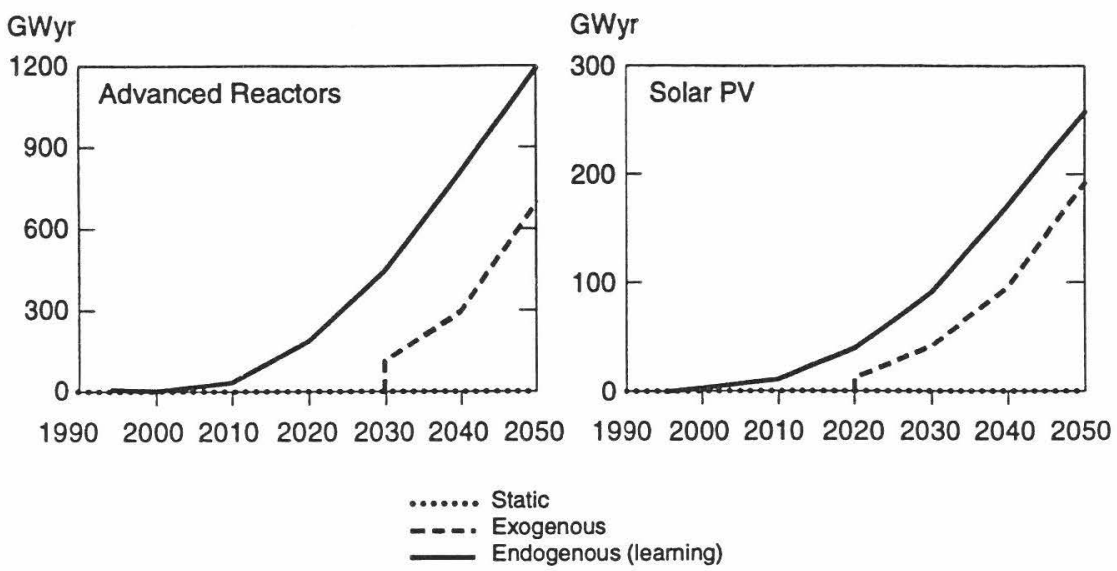

Fig. 4. Diffusion of new energy technologies in the global electricity sector using three models of technology dynamics: static, exogenous, and endogenous. Model calculations are for a typical high growth demand scenario (case A from IIASA-WEC, 1995).

market penetration of these technologies up to 2030 , are introduced, the optimal choice for the model is to wait until the new technologies would become competitive around 2020-2030 and only then begin investments. This is a classical case of technological change falling 'from heaven'. Conversely, with endogenized technological change, the model can influence future technology improvements by intervening investments. For both systems displayed in Fig. 4 market penetration starts earlier and market shares by 2050 are higher than in the case with exogenous technology dynamics, not to mention the static technology case.

\section{Implications for the timing of mitigation measures}

The model of technology dynamics chosen for the analysis influences the timing and levels of investment into new technologies. This also holds for measures to mitigate global change. Dynamic technology characteristics allow for more freedom in intertemporal allocation of resources and emission reduction efforts. Cheaper and more efficient technologies allow for a faster reduction of $\mathrm{CO}_{2}$ emissions in the shorter term, leaving more freedom for higher emission levels in the longer run. Obviously, also costs of meeting particular emission limits depend critically on technology dynamics.

Fig. 5 shows the results of alternative model runs with the same stabilization target as in our previous analysis. Here we show the short-term (to 2035) implications on emission paths of alternative models to represent technological change: static versus endogenous dynamics. Again we have performed calculations with 


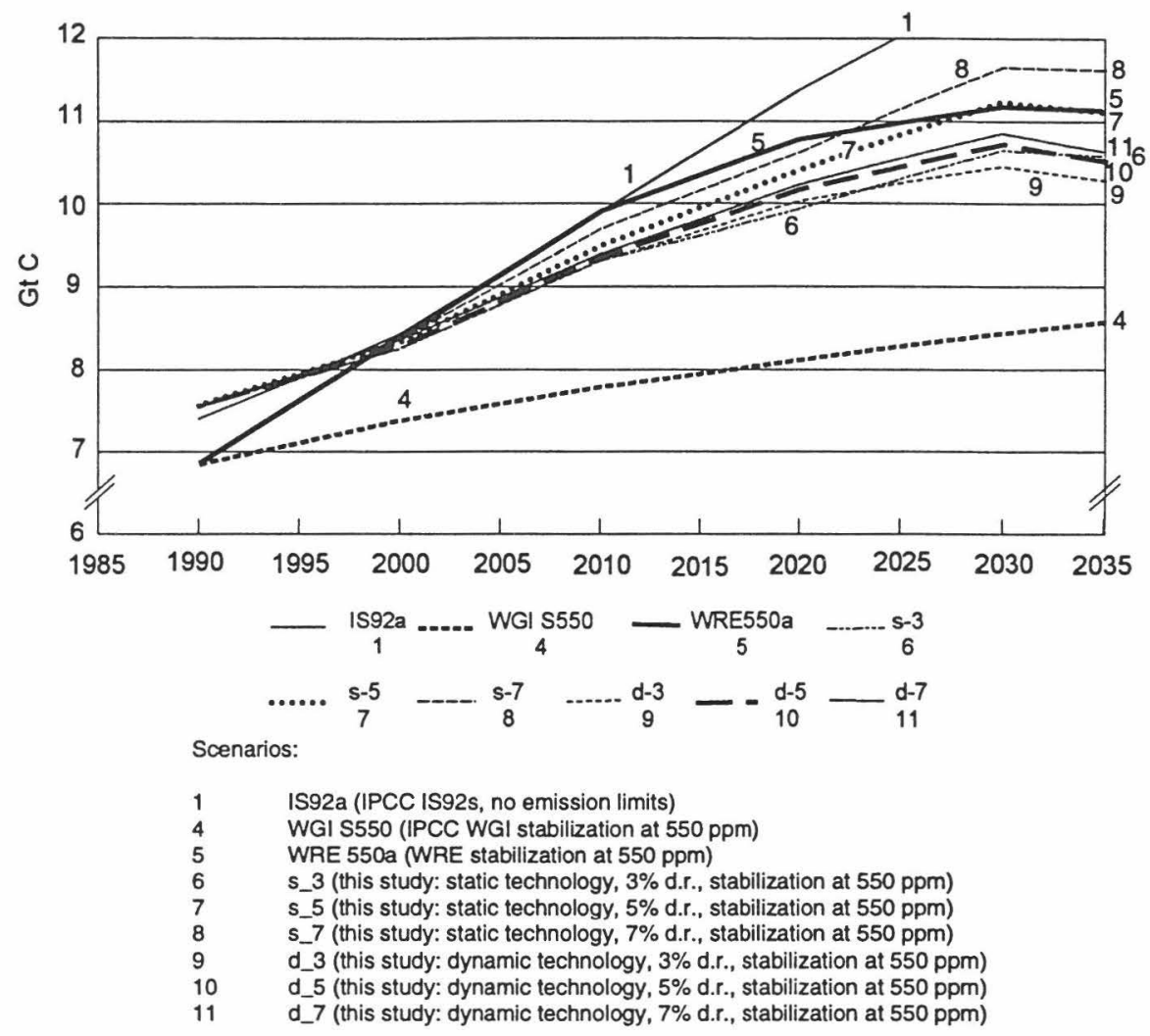

Fig. 5. Alternative scenarios for stabilization at $550 \mathrm{ppmv} \mathrm{CO}_{2}$ : static technology with 3,5 and $7 \%$ discount rate and dynamic technology with 3,5 and $7 \%$ discount rate compared to IS92a, WRE and IPCC WGI scenarios. Note that only emission trends to 2035 are shown to highlight differences in short-term emission trajectories.

discount rates varied between 3,5 , and $7 \%$ and compare our results with the IS92a and WRE and IPCC WGI scenarios.

Overall, we find that the influence of the representation of technological change on near-term emission paths is as important as the influence of the discount rate. Typically, the endogenous technology dynamics scenarios have lower short-term emissions resulting from the gradual introduction of low- and zero-carbon technologies that need to be experimented with in order to prepare their massive application in the post-2050 period. The short-term emission path of the endogenous technology dynamics (with $5 \%$ discount rate) shows in fact a similar pattern as the simulation with static technology and a discount rate of $3 \%$. However, the causes of this similar effect are entirely different: a lower discount rate just reduces the tendency to postpone costly measures into the far future; this far future has a larger impact on the overall result. Incorporating technological 
dynamics in the model allows, through additional investments in new technologies and consequently improving the performance of these technologies, to realize economic returns on upfront investments, in the form of the availability of cheap and efficient technologies with lower carbon emissions. This effect becomes transparent when looking at the computed shadow price of the carbon constraint of our scenarios. In the static technology cases shadow prices increase continuously, from $10 \$ / \mathrm{tC}$ in the year 2000 to some $1200 \$ / \mathrm{tC}$ towards the end of the 21 st century. In the endogenous dynamics case shadow prices of the carbon constraint are much lower, leveling off at $500 \$$ per ton of carbon. ${ }^{10}$ Consequently, by initial higher investments in new technologies and the resulting technological learning these stimulate, massive longer-term benefits accrue. Both lower emission reduction costs and lower $\mathrm{CO}_{2}$ emissions can be realized compared to the static technology case.

We emphasize the results of the endogenous technology dynamics model simulations because of its importance for the policy implications discussion of the WRE analysis, replicated by us for this paper.

However, we once again confer with the basic quantitative results of the WRE analysis. Independent of the issue of discount rate, or of static versus endogenous technology dynamics, the largest divide in short-term emission trajectories remains between the IPCC results (based on a carbon cycle model intercomparison) and those from models that additionally embrace an intertemporal optimization perspective, while still arriving at comparable long-term $\mathrm{CO}_{2}$ concentration stabilization targets. What matters most for near-term emissions profiles (and hence the necessity to adopt mitigation measures) is whether cost effectiveness criteria are considered or not. Thus, the ultimate divide may be a disciplinary one. Between natural sciences on one hand and economics on the other.

\section{Conclusion: policy implications}

We used a coupled carbon-cycle and energy systems engineering model to analyze the future time path of carbon emissions under an illustrative $\mathrm{CO}_{2}$ concentration stabilization limit of $550 \mathrm{ppm}$. Our findings confirm the basic

\footnotetext{
${ }^{10}$ Evidently, levels and profiles of shadow prices are sensitive to variations in the discount rate. Above numbers correspond to calculations with a $5 \%$ discount rate. As a robust analytical result we find that under full temporal and spatial flexibility carbon shadow prices (imputed tax levels) start off from low values in the range of $1-10 \$ / \mathrm{tC}$ and increase continuously over time, roughly at the rate of the discount rate. This means that, with a higher discount rate, near-term carbon shadow prices are ceteris paribus lower, but long-term shadow prices are higher. Note that our short-term carbon shadow prices correspond well with the short-term values obtained by Nordhaus (1994). Our long-term (2100) carbon shadow prices above $1000 \$ / \mathrm{tC}$ of course are in stark contrast to values of $20 \$ / \mathrm{tC}$ suggested by Nordhaus (1994). The reason is that we use a fixed, exogenously given $\mathrm{CO}_{2}$ concentration limit for our calculations, whereas Nordhaus estimates an intertemporal optimum weighting mitigation costs against a particular climate damage function that does not lead to any $\mathrm{CO}_{2}$ concentration stabilization.
} 
emission pattern as found by WRE: global emissions rise initially, pass through stabilization, in order to decline in the second half of the 21st century. We show that for a given $\mathrm{CO}_{2}$ concentration stabilization target, emission trajectories under inter-temporal optimization depend mainly on two factors: the discount rate, and the representation of technological change as either static or endogenously dynamic. We obtain a similar near-term emission time path as WRE when using a model with static technology and a discount rate of $7 \%$. We obtain a trajectory with lower emissions in the near-term when using a lower discount rate and/or treating technology dynamics endogenously in the model. Differences between alternative model formulations are sufficiently small as to be of secondary importance when compared to treating $\mathrm{CO}_{2}$ concentration stabilization as an inter-temporal optimization problem or not. Whereas our results thus confirm the computational results of WRE, we arrive nonetheless at different policy conclusions.

\subsection{Act now or later?}

Over the short-term emissions consistent with long-term $\mathrm{CO}_{2}$ concentration stabilization do not differ markedly from those typical of 'business as usual' or 'do nothing' scenarios. Initially they are only slightly lower and differences widen only in the longer-term. Typically, for a stabilization target of $550 \mathrm{ppm}$ global carbon emissions can rise to some $11 \mathrm{GtC}$ around 2030, need to stabilize thereafter, and start to decline significantly only after 2050. Does this mean that over the short-term we can follow 'business as usual' policies? According to our understanding of technological change as an endogenous process we cannot. If long-term emission reduction is the goal, we cannot follow 'business as usual' even in the short-term. Action needs to start now. Action does not necessarily mean aggressive short-term emission reductions but rather enhanced $\mathrm{R} \& \mathrm{D}^{11}$ and technology demonstration efforts that stimulate technological learning. These are the necessary preconditions that long-term reduction targets can be met with improved technology and at costs lower than today or lower than in the case where technologies remain unchanged.

We arrive at this conclusion considering technological change as an endogenous process, and after substantial methodological advances in the treatment of nonconvexities and stochasticity have been achieved in models of technology choice. $\mathrm{R} \& \mathrm{D}$ and technological learning in niche markets and via gradually expanding investments (as opposed to mission oriented crash programs) ${ }^{12}$ yield substantial long-term returns. But they also require dedicated efforts and a long time (and acceptance of possible failures) to bear fruits. This introduces an additional time

\footnotetext{
${ }^{11}$ The importance of $\mathrm{R} \& \mathrm{D}$ in preparing for climate change response strategies was also emphasized by Wigley et al. (1996). Note that we argue for R \& D and technological learning as strategies for preparing for long-term technological change rather as opposed to spend money exclusively on short-term emission reduction efforts. This should make additional $\mathrm{R} \& \mathrm{D}$ resources available and reduce thus possible 'crowding out' phenomena in $\mathrm{R} \& \mathrm{D}$ resource allocation due to climate policy intervention (for a discussion of the latter see Goulder and Schneider, 1996).
} 
constraint for changes in the technological landscape beyond that of the longevity of the capital stock of the energy sector and of infrastructures (Grübler, 1996) and of 'technological inertia' (Grubb et al., 1994) in general.

\subsection{Two final caveats}

We close by pointing out two further critical issues: uncertainty, and the possible mismatch between the world of economic models and that of climate policy.

\subsubsection{Uncertainty}

The numerical precision of our (and any similar) model calculations should not distract from the basic fact that uncertainty abounds. First, like WRE we have performed our calculations with a 'best guess' parametrization carbon cycle model. But evidently both our understanding and our models of the carbon cycle are uncertain. For any given level and date of $\mathrm{CO}_{2}$ concentration stabilization (that science continues to be unable to suggest) the timing of emission reductions debate is dwarfed by the spread in allowable emission profiles resulting from carbon cycle uncertainties. ${ }^{13}$ We do not know the future evolution of energy demand, we are uncertain about potentials and timing of technological progress, we remain uncertain about which discount rate to use, uncertain how to balance mitigation costs with the benefits of a reduced warming signal, etc. etc.

The real issue therefore is not to debate optimal timing, but rather how to prepare best for future contingencies should drastic emission reduction indeed become required. Analyses in the domain of energy technologies have shown that optimal contingency polices vis à vis uncertainty all entail diversification and 'prepare early for possible action later' strategies. These findings emerge from the treatment of technology characteristics as inherently uncertain (as done for instance in the stochastic programming exercises reported in Golodnikov et al. (1995), Messner et al. (1996), and Grübler and Messner (1996)). And they emerge also from models that treat technological dynamics (learning) as well as other salient influencing variables as inherently uncertain (cf. Grübler and Gritsevskii, 1997). The optimal technology 'hedging'14 strategy in all cases is to stimulate $\mathrm{R} \& \mathrm{D}$, experimentation, niche markets, i.e. technological learning. And like all learning, technological learning cannot start early enough. Choosing the most appropriate policy instruments to achieve this remains open to further research and debate.

\footnotetext{
${ }^{12}$ As evidenced by past failures, e.g. fast feeder reactor or synfuel development programs, gradual technology development via experimentation and learning under decentralized decision making might be both economically and socially superior to large-scale, centralized (and government sponsored) mission oriented energy technology programs. However, experimentation and learning require long-time horizons for both planning and implementation, which is frequently beyond the time frame of short-term market decisions or of policy.

${ }^{13}$ Schimmel et al. (1995), reporting a comparison of various models, illustrate this uncertainty margin.

${ }^{14}$ See also Manne and Richels (1995) on hedging strategies, particularly in the domain of reduction of climate uncertainties.
} 


\subsubsection{Decision paradigms: political versus economic}

Throughout our calculations we have assumed full intertemporal and spatial flexibility in emission reduction; i.e. the model runs presuppose that emissions are reduced when and where it is cheapest to do so in order to remain within the long-term global $\mathrm{CO}_{2}$ concentration stabilization target. This economic concept of cost effectiveness in emission abatement may, however, be politically naive as most of the current negotiations within the FCCC focus on short-term quantified emission reduction limits and less on mechanisms and instruments and how these could be achieved most cost effectively, e.g. through joint implementation, tradable permits, etc. (cf. Victor and MacDonald, 1997). This mismatch between the world of economic calculus and that of political negotiations may well turn out to be more important for assessing the economic impacts of $\mathrm{CO}_{2}$ emission reductions, than the issue of optimal timing of emission abatement.

\section{References}

Amann, M., Cofala, J., Dörfner, P., Gyarfas, F., Schöpp, W., 1995. Impacts of energy scenarios on regional acidification. Report WEC Project 4 on Environment, Working Group C Local and Regional Energy Related Environmental Issues. World Energy Council, London.

Argote, L., Epple, D., 1990. Learning curves in manufacturing. Science 247, 920-924.

Arrow, K., 1962. The economic implications of learning by doing. Review of Economic Studies 29, $155-173$.

Cantley, M.F., Sahal, D., 1980. Who learns what? A conceptual description of capability and learning in technological systems. RR-80-042. International Institute for Applied Systems Analysis, Laxenburg, Austria.

Christiansson, L., 1995. Diffusion and learning curves of renewable energy technologies. WP-95-126, International Institute for Applied Systems Analysis, Laxenburg, Austria.

Clair, D.R., 1983. The perils of hanging on. European Petrochemical Association, 17th Annual Meeting, Monte Carlo.

Golodnikov, A., Gritsevskii, A., Messner, S., 1995. A stochastic version of the dynamic linear programming model MESSAGE III. WP-95-94, International Institute for Applied Systems Analysis, Laxenburg, Austria.

Goulder, L.H., Schneider, S.H., 1996. Induced technical change, crowding out, and the attractiveness of $\mathrm{CO}_{2}$ emissions abatement. Mimeo, Stanford University, Stanford, CA, USA.

Grubb, M., Duong, M.H., Chapuis, T., 1994. Optimizing climate change abatement responses: on inertia and induced technical development. In: Nakićenović, N., Nordhaus, W.D., Richels, R., Toth, F.L. (Eds.), Integrative Assessment of Mitigation, Impacts and Adaptation to Climate Change. CP-94-9, International Institute for Applied Systems Analysis, Laxenburg, Austria, pp. 513-534.

Grübler, A., 1996. Time for a change: on the patterns of diffusion of innovation. Daedalus 125, 19-42.

Grübler, A., Gritsevskii, A., 1997. A model of endogenous technological change through uncertain returns on learning ( $R \& D$ and investments). Paper presented at the International Workshop on Induced Technical Change and the Environment, 26-27 June, 1997. IIASA, Laxenburg, Austria.

Grübler, A., Messner, S., 1996. Technological uncertainty. In: Nakićenović, N., Nordhaus, W.D., Richels, R., Toth, F.L. (Eds.), Climate Change: Integrating Science, Economics, and Policy. CP-96-1, International Institute for Applied Systems Analysis, Laxenburg, Austria, pp. 295-314.

Grübler, A., Nakićenović, N., 1996. Decarbonizing the global energy system. Technological Forecasting \& Social Change 53, 97-110.

IIASA-WEC International Institute for Applied Systems Analysis and World Energy Council, 1995. Global Energy, Perspectives to 2050 and Beyond. World Energy Council, London. 
IPCC Intergovernmental Panel on Climate Change, 1995. Climate Change 1994: Radiative Forcing of Climate Change, and An Evaluation of the IPCC IS92 Emission Scenarios. Cambridge University Press, Cambridge, UK.

IPCC Intergovernmental Panel on Climate Change, 1996. IPCC Second Assessment: Climate Change 1995. IPCC, Geneva, Switzerland.

Manne, A.S., Richels, R.G., 1995. The greenhouse debate - economic efficiency, burden, sharing, and hedging strategies. The Energy Journal 16, 1-37.

Messner, S., Strubegger, M., 1995. User's guide for MESSAGE III. WP-95-96, International Institute for Applied Systems Analysis, Laxenburg, Austria.

Messner, S., 1997a. Endogenized technological learning in an energy systems model. Journal of Evolutionary Economics 7, 291-313.

Messner, S., 1997b. Synergies and conflicts of sulfur and carbon mitigation strategies. Energy Conversion and Management 38, 629-634.

Messner, S., Golodnikov, A., Gritsevskii, A., 1996. A stochastic version of the dynamic linear programming model MESSAGE III. Energy 21, 775-784.

Messner, S., 1995. Endogenized technological learning in an energy systems model. WP-95-114, International Institute for Applied Systems Analysis, Laxenburg, Austria.

Nakićenović, N., 1996. Technological change and learning. In: Nakićenović, N., Nordhaus, W.D., Richels, R., Toth, F.L. (Eds.), Climate Change: Integrating Science, Economics, and Policy. CP-96-1, International Institute for Applied Systems Analysis, Laxenburg, Austria, pp. 271-294.

Nakićenović, N., 1997. Technological change as a learning process. Paper presented at the International Workshop on Induced Technical Change and the Environment, 26-27 June 1997, IIASA, Laxenburg, Austria.

Nordhaus, W.D., Van der Heyden, L., 1983. Induced technical change: a programming approach. In: Schurr, S.H., Sonnenblum, S., Wood, D.O. (Eds.), Energy, Productivity, and Economic Growth. Oelgeschlager, Gunn \& Hain, Cambridge, MA, pp. 379-404.

Nordhaus, W.D., 1994. The ghosts of climates past and the specters of climates future. In: Nakićenović, N., Nordhaus, W.D., Richels, R., Toth, F.L. (Eds.), Integrative Assessment of Mitigation, Impacts and Adaptation to Climate Change. CP-94-9, International Institute for Applied Systems Analysis, Laxenburg, Austria, pp. 35-62.

Pepper, W., Legett, J., Swart, R., Wasson, J., Edmonds, J., Mintzer, I., 1992. Emission scenarios for the IPCC, an update: assumptions, methodology and results. Intergovernmental Panel on Climate Change, Geneva, Switzerland.

Posch, M., Hettelingh, J.P., Alcamo, J., Krol, M., 1996. Integrated scenarios of acidification and climate change in Asia. Global Environmental Change 6, 375-394.

Rogner, H.H., Nakićenović, N., 1995. Zur Rolle des Schwefels in der Klimadebatte. Energiewirtschaftliche Tagesfragen 46, 731-735.

Rosenberg, N., 1982. Inside the black box: technology and economics. Cambridge University Press, Cambridge, UK.

Schimmel, D., Enting, I.G., Heimann, M., Wigley, T.M.L., Raynaud, D., Alves, D., Siegenthaller, U., 1995. $\mathrm{CO}_{2}$ and the carbon cycle. In: Radiative Forcing of Climate Change. IPCC Working Group I, and Cambridge University Press, Cambridge, UK.

Strubegger, M., Reitgruber, I., 1995. Statistical analysis of investment costs for power generation technologies. WP-95-109, International Institute for Applied Systems Analysis, Laxenburg, Austria.

Victor, D., MacDonald, G., 1997. Regulating global warming: success in Kyoto. Linkages 2(4), 1-4 (http://www.iisd.ca/linkages/journal).

Watanabe, C., 1995. Identification of the role of renewable energy. Renewable Energy 6, 237-274.

Watanabe, C., 1997. Tokyo Institute of Technology, personal communication based on MITI statistics.

Wigley, T.M.L., 1991. A simple inverse carbon cycle model. Global Biogeochemical Cycles 5, 373-382.

Wigley, T., Richels, R., Edmonds, J., 1996. Economic and environmental choices in the stabilization of atmospheric $\mathrm{CO}_{2}$ concentrations. Nature 739, 240-243.

Wright, T.P., 1936. Factors affecting the costs of airplanes. Journal of the Aeronautical Sciences 3, 122-128. 